\title{
Energy expenditure in chronic stroke patients playing Wii Sports: a pilot study
}

\author{
Henri L Hurkmans ${ }^{1 *}$, Gerard M Ribbers ${ }^{1,2}$, Marjolein F Streur-Kranenburg ${ }^{1}$, Henk J Stam ${ }^{1}$ and \\ Rita J van den Berg-Emons ${ }^{1}$
}

\begin{abstract}
Background: Stroke is one of the leading causes of long-term disability in modern western countries. Stroke survivors often have functional limitations which might lead to a vicious circle of reduced physical activity, deconditioning and further physical deterioration. Current evidence suggests that routine moderate- or vigorousintensity physical activity is essential for maintenance and improvement of health among stroke survivors. Nevertheless, long-term participation in physical activities is low among people with disabilities. Active video games, such as Nintendo Wii Sports, might maintain interest and improve long-term participation in physical activities; however, the intensity of physical activity among chronic stroke patients while playing Wii Sports is unknown. We investigated the energy expenditure of chronic stroke patients while playing Wii Sports tennis and boxing.
\end{abstract}

Methods: Ten chronic ( $\geq 6$ months) stroke patients comprising a convenience sample, who were able to walk independently on level ground, were recruited from a rehabilitation centre. They were instructed to play Wii Sports tennis and boxing in random order for 15 minutes each, with a 10-minute break between games. A portable gas analyzer was used to measure oxygen uptake $\left(\mathrm{VO}_{2}\right)$ during sitting and during Wii Sports game play. Energy expenditure was expressed in metabolic equivalents (METs), calculated as $\mathrm{VO}_{2}$ during $\mathrm{Wii}$ Sports divided by $\mathrm{VO}_{2}$ during sitting. We classified physical activity as moderate (3-6 METs) or vigorous (> 6 METs) according to the American College of Sports Medicine and the American Heart Association Guidelines.

Results: Among the 10 chronic stroke patients, 3 were unable to play tennis because they had problems with timing of hitting the ball, and 2 were excluded from the boxing group because of a technical problem with the portable gas analyzer. The mean $( \pm$ SD) energy expenditure during Wii Sports game play was $3.7( \pm 0.6)$ METs for tennis and 4.1 ( \pm 0.7) METs for boxing. All 8 participants who played boxing and 6 of the 7 who played tennis attained energy expenditures $>3$ METs.

Conclusions: With the exception of one patient in the tennis group, chronic stroke patients played Wii Sports tennis and boxing at moderate-intensity, sufficient for maintaining and improving health in this population.

\section{Background}

Stroke is one of the leading causes of long-term disability in modern western countries [1]. As a consequence of European population aging, the number of strokes is predicted to increase from approximately 1.1 million per year in 2000 to 1.5 million per year in 2025 [2]. Worldwide stroke prevalence ranges from 5-10 per 1000

\footnotetext{
* Correspondence: h.hurkmans@erasmusmc.nl

'Department of Rehabilitation Medicine and Physical Therapy, Erasmus MC University Medical Center, P.O. Box 2040, 3000 CA Rotterdam, The Netherlands

Full list of author information is available at the end of the article
}

among all age groups and from 46-73 per 1000 among persons aged $\geq 65$ years [3]. There is a growing need for cost-effective treatment for stroke patients, including rehabilitation and tertiary prevention.

Stroke survivors often become deconditioned with an aerobic capacity about half that of age-matched controls [4-6]. Low aerobic capacity compromises functional mobility after stroke $[7,8]$. This might lead to a vicious circle of physical inactivity and further physical deterioration [4,9]. Mobility status from 1-3 years after stroke significantly deteriorates in $21 \%$ of patients, resulting in reduction of activities of daily living, loss of

\section{() Biomed Central}


independence, and social isolation [10]. Physical inactivity might also be a risk factor for recurrent stroke and cardiac events by promoting insulin resistance [5,11-13]. Current guidelines, therefore, recommend that routine moderate- or vigorous-intensity physical activity is needed for stroke survivors to improve and maintain their health $[4,14]$. However, long-term participation in physical activities is low among people with disabilities as a result of person related factors (e.g. reduced mobility, social isolation) and environmental factors (e.g. limited access to stores and buildings, transport, and availability of equipment) [4,15-17].

Active video game (exergame) systems, such as Nintendo Wii Sports, are innovative and potential technologies that might improve daily physical activity levels for persons with chronic physical disabilities. Previous studies reported a mean energy expenditure of 3-4 metabolic equivalents (METs) among able-bodied adults during Wii tennis and boxing $[18,19]$. This suggests that exergames have the potential to promote and maintain health, according to the American College of Sports Medicine and American Heart Association (ACSM/ AHA) Guidelines on physical activity and public health [20]. Practical advantages of exergaming include the ability to train at home with or without online supervision, thus reducing healthcare costs [21]. Furthermore, exergames can provide real-time feedback on performance and progress [22]. They are also enjoyable, and can be performed with able-bodied relatives or friends or in virtual training groups to enhance compliance [22].

Wii Sports is designed for entertainment rather than therapy, which might limit its usability for stroke rehabilitation. However, in a recent pilot study the Wii gaming technology was found to be a safe, feasible and potentially effective alternative to promote motor recovery after stroke [23]. It is unknown, nonetheless, whether Wii Sports is of sufficient intensity (moderate or vigorous) to promote and maintain health in this population. Stroke-specific factors, including elevated muscle tone and postural instability, might have a large demand on oxygen uptake $[4,6]$. Conversely, these stroke-specific factors might lead to less intense gameplay and consequently lower energy expenditure.

We performed a proof-of-principle pilot study to determine the energy expenditure of chronic stroke patients while playing Wii-Sports. Our hypothesis was that the energy expenditure would indicate moderateor vigorous-intensity and meet the ACSM/AHA guidelines to improve and maintain health.

\section{Methods}

\section{Participants}

A convenience sample of 10 persons with chronic stroke was recruited from Rijndam Rehabilitation Centre in the
Netherlands. Patients were included if they experienced an ischemic infarct $\geq 6$ months prior, and were classified as Functional Ambulation Category (FAC) independence level 3, 4 or 5 [24]. Patients with a history of psychiatric disorders or conditions that might influence physical activity and fitness (e.g. lung disease, rheumatoid arthritis) or impair the safety of physical strain (e.g. cardiac disease) were excluded. Additionally, patients were excluded if they could not understand or were unable to perform research tasks as a result of severe cognitive or linguistic disorders or speech barriers, or if they experienced pain in the affected arm and hand. None of the patients were familiar with the Wii before the study. Eligible persons who provided informed consent were included in the study. Patient characteristics were collected from the patient file, including demographics (age, gender), stroke severity using the Bamford scale [25], upper extremity strength and spasticity from the affected side using de Medical Research Council (MRC) scale [26] and the Modified Ashworth Scale [27], balance using the Berg Balance Scale (BBS) [28], and disability based on the Modified Rankin Scale [29]. The protocol was approved by the Medical Ethical Committee of Erasmus MC.

\section{Instruments}

The Nintendo Wii, a home video game console, and the Wii Sports games tennis and boxing were used in the study [30]. The games are played with the Wii remote, which is the primary controller for the console [31]. The Wii remote is a wireless (Bluetooth) device that has a 3-axis accelerometer sensor inside to measure motion in all directions and all speeds. Because of its motion sensing capability, the user is in contact with and can manipulate items on the screen via gesture recognition. For certain Wii games, like Wii boxing, another controller is needed: the Nunchuk. Like the Wii Remote, the Nunchuk also provides a 3-axis accelerometer for motion-sensing and tilting, but without a speaker, a rumble function, or a pointer function. Participants played the Wii games in our department's Exergame Lab, which has a relatively large playing area $(5 \times 6$ meter) with a $1.5 \times 2.5$ meter beamer projection on the wall along with stereo speakers to provide the visual and audio stimuli (Figure 1).

\section{Anthropometric and physiologic measurements}

Body mass was measured within $0.1 \mathrm{~kg}$ accuracy using a calibrated electronic scale (KORONA, Leeds, UK); body height was measured within $0.1 \mathrm{~cm}$ accuracy using a wall mounted metal anthropometer (SECA, Hamburg, Germany). Body mass and height were measured with shoes off. Skinfold thickness was measured with a Harpenden Caliper (Burgess Hill, UK) twice on the right 


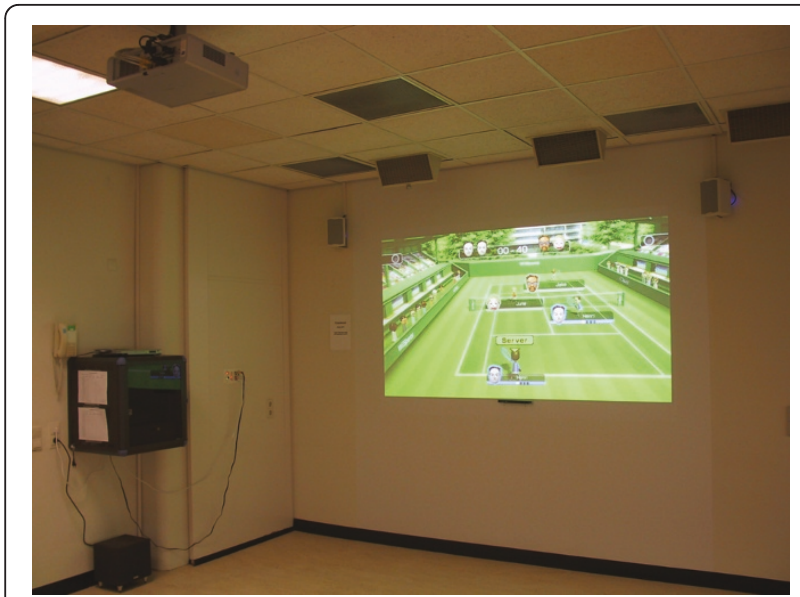

Figure 1 The Exergame Lab at our department.

side of the body at each of four sites (biceps brachii, triceps brachii, subscapular, and suprailiac). The caliper has a measuring range of 0 to $80 \mathrm{~mm}$, an accuracy of $99 \%$, and a reliability within $0.20 \mathrm{~mm}$. Body fat percentage was calculated according to the equations of Durnin and Womersley [32]. This calculation was then used to determine fat-free mass.

Energy expenditures during game play, sitting, and standing were assessed using a validated portable indirect calorimeter (Cosmed $\mathrm{K} \mathrm{b}^{2}$, COSMED, Rome, Italy) [33-38]. Oxygen and carbon dioxide sensors were calibrated with standard gases of known oxygen (16\%) and carbon dioxide (5\%) concentrations before each Wii tennis and boxing session. A 2-liter volume calibration syringe was used to calibrate the respiratory volume. We measured heart rate (HR) using a Polar T61 heart rate monitor (Polar Electro, Kempele, Finland), which was placed on the participant's chest and connected to the calorimeter. Selfperceived exercise intensity was measured using the modified Borg scale with 0 being "nothing at all" and 10 being "very, very strong" [39,40]. All anthropometric and physiologic measurements were obtained by the same investigator (MF Streur-Kranenburg).

\section{Experimental trial}

Gas exchange measurements were performed during 5 minutes of chair-sitting and during 5 minutes of standing still. Next, participants had up to five minutes to familiarize themselves with the Wii controllers (Wii remote and Nunchuk) and the tennis and boxing games. Then, the participants rested for a minimum of $5 \mathrm{~min}$ utes, or until HR had decreased to chair-sitting level.

After resting, the participants played Wii Sports tennis and boxing for 15 minutes each, in random order, with a 10-minute minimum intervening rest period, or until HR had decreased to chair-sitting level. Patients hold the Wii remote in the dominant hand, which could be the affected or non-affected hand. At the conclusion of each tennis match or boxing game, participants restarted the game as quickly as possible and continued to play for a total of 15 minutes. Following each 15 minute game play session, participants rated their perceived exertion using the modified Borg Scale. Participants were allowed to play the game in their own manner and at their own pace. To ensure participant safety and safe handling of measurement equipment, two researchers stood beside the participants during Wii game play.

\section{Data analysis}

Mean ( \pm standard deviation) $\mathrm{VO}_{2}$ was calculated for the final 2.5 minutes during sitting and standing, and for the entire 15 minute duration of game play. We calculated energy expenditure, expressed in METs, as the $\mathrm{VO}_{2}$ during game play divided by the $\mathrm{VO}_{2}$ during sitting. Wilcoxon signed rank tests were used to compare the physiologic variables and perceived exertion measured during Wii tennis with Wii boxing. Wilcoxon signed rank tests were also used to compare physiologic variables measured during game play with those measured during sitting and standing. We used SPSS 16.0 for statistical analyses and set the significance level at $\mathrm{P} \leq 0.05$.

\section{Results}

Five participants had a maximum score of 5 on the FAC, indicating an ability to ambulate on non-level and

Table 1 Characteristics of study participants

\begin{tabular}{lcc}
\hline & $\begin{array}{c}\text { Tennis } \\
(\mathbf{n}=\mathbf{7})\end{array}$ & $\begin{array}{c}\text { Boxing } \\
(\mathbf{n}=\mathbf{8})\end{array}$ \\
\hline Men/women (n) & $3 / 4$ & $5 / 3$ \\
Age (yrs) & $48(33-68)$ & $56(33-74)$ \\
Mass (kg) & $84.5 \pm 19.7$ & $81.9 \pm 10.3$ \\
Handedness, right & 7 & 8 \\
Sum of skinfolds (mm) & $91.9 \pm 27.2$ & $83.7 \pm 15.9$ \\
\% Body fat & $35.6 \pm 7.0$ & $34.6 \pm 5.8$ \\
Fat-free Mass (kg) & $53.9 \pm 10.6$ & $53.5 \pm 7.7$ \\
Height (cm) & $171.9 \pm 7.2$ & $172.6 \pm 7.5$ \\
Body mass index (kg/m $\left.{ }^{2}\right)$ & $28.4 \pm 5.4$ & $27.5 \pm 2.7$ \\
Time post-stroke (months) & $34.3(9-119)$ & $18.6(9-30)$ \\
Stroke severity: PACS/POCS & $4 / 3$ & $6 / 2$ \\
Affected side, right & 4 & 6 \\
\multicolumn{1}{c}{ MRC } & $4.1(1-5)$ & $4.3(1-5)$ \\
$\quad$ MAS & $0.4(0-2)$ & $0.5(0-2)$ \\
Balance (BBS) & $54.7(52-56)$ & $54.9(52-56)$ \\
mRS & $1.7(1-3)$ & $2.1(1-3)$ \\
\hline Values are mean \pm standard deviations & (m) & mean (rang). PACl \\
\hline
\end{tabular}

Values are mean \pm standard deviations or mean (range). $\mathrm{PACl}=$ partial anterior circulation syndrome, $\mathrm{POCl}=$ posterior circulation syndrome; $\mathrm{MRC}=$ Medical Research Council; MAS = Modified Ashworth scale; BBS = Berg Balance Scale; $\mathrm{mRS}=$ modified Rankin Scale. 
level surfaces, stairs, and inclines, one of whom used an orthosis and a walking-cane. Three persons scored a 4 on the FAC, indicating an ability to walk independently on level surfaces, but required help on uneven surfaces, stairs, or inclines. Participant characteristics are summarized in Table 1 for the participants that played Wii tennis $(n=7)$ and boxing $(n=8)$. Three participants were unable to play the tennis game, because of problems with timing of hitting the ball. A technical problem with the calorimeter invalidated $\mathrm{VO}_{2}$ data collection from 2 participants during boxing.

The mean (SD) $\mathrm{VO}_{2}$ during sitting was $3.0(0.8) \mathrm{ml} /$ $\mathrm{kg} / \mathrm{min}$ for the participants who played tennis and 2.9 (0.7) $\mathrm{ml} / \mathrm{kg} / \mathrm{min}$ for those who played boxing. For standing the mean $\mathrm{VO}_{2}$ was $3.6(1.1) \mathrm{ml} / \mathrm{kg} / \mathrm{min}$ for the participants who played tennis and $3.8(0.9) \mathrm{ml} / \mathrm{kg} /$ min for those who played boxing. Compared with sitting, $\mathrm{VO}_{2}$ was $30 \%$ higher when standing for the tennis group and $31 \%$ higher for the boxing group $(\mathrm{P}=0.01)$. Wii Sports tennis increased the $\mathrm{VO}_{2} 267 \%$ compared with sitting ( $\mathrm{P}=0.02)$, and $205 \%$ compared with standing $(\mathrm{P}=0.02)$. Wii Sports boxing increased $\mathrm{VO}_{2} 310 \%$ compared with sitting $(\mathrm{P}=0.01)$, and $213 \%$ compared with standing $(P=0.01)$. Energy expenditure was higher for Wii boxing (4.1 METs) compared to Wii tennis (3.7 METs); however, this difference was not significant $(\mathrm{P}=0.50)$ (Table 2$)$. For all participants, the energy expenditure was $\geq 3$ METs during boxing (range 3.4 - 5.7 METs) (Figure 2). Only one participant had energy expenditure $<3$ METs during tennis (range 2.7 - 5.0 METs). The mean perceived exertion was rated higher for Wii Sports boxing (5.3) than for tennis (4.1) $(\mathrm{P}=0.034)$ (Table 2$)$. The individual perceived exertion rates and MET values for tennis and boxing are presented in table 3 .

Table 2 Cardiorespiratory variables, energy expenditure, and perceived exertion of the $\mathbf{1 5}$ minutes Wii game play

\begin{tabular}{lccc}
\hline & Tennis $(\mathbf{n}=\mathbf{7})$ & Boxing $(\mathbf{n}=\mathbf{8})$ & $\boldsymbol{P}$ \\
\hline $\mathrm{VO}_{2}(\mathrm{ml} / \mathrm{min})$ & $891.6(249.1)$ & $980.1(319.2)$ & 0.345 \\
$\mathrm{VO}_{2}(\mathrm{~m} / \mathrm{kg} / \mathrm{min})$ & $11.0(3.9)$ & $11.9(3.3)$ & 0.345 \\
$\mathrm{VO}_{2}(\mathrm{~m} / \mathrm{FFM} / \mathrm{min})$ & $17.0(5.2)$ & $18.1(4.4)$ & 0.345 \\
$\mathrm{HR}(\mathrm{beats} / \mathrm{min})$ & $96.8(14.7)$ & $106.1(20.0)$ & 0.225 \\
$\mathrm{VE}_{\mathrm{E}}(\mathrm{L} / \mathrm{min})$ & $25.7(4.7)$ & $33.2(10.3)$ & 0.225 \\
$\mathrm{RER}$ & $0.91(0.06)$ & $0.95(0.07)$ & 0.500 \\
Energy expenditure (METs) & $3.7(0.8)$ & $4.1(0.7)$ & 0.500 \\
Perceived exertion & $4.1(1.2)$ & $5.3(2.7)$ & 0.034 \\
\hline
\end{tabular}

Values are mean \pm standard deviation

$\mathrm{VO}_{2}=$ oxygen uptake

$\mathrm{FFM}=$ fat free mass

$\mathrm{HR}=$ heart rate

$\mathrm{V}_{\mathrm{E}}=$ pulmonary ventilation

$\mathrm{RER}=$ respiratory exchange rate

METs = metabolic equivalents

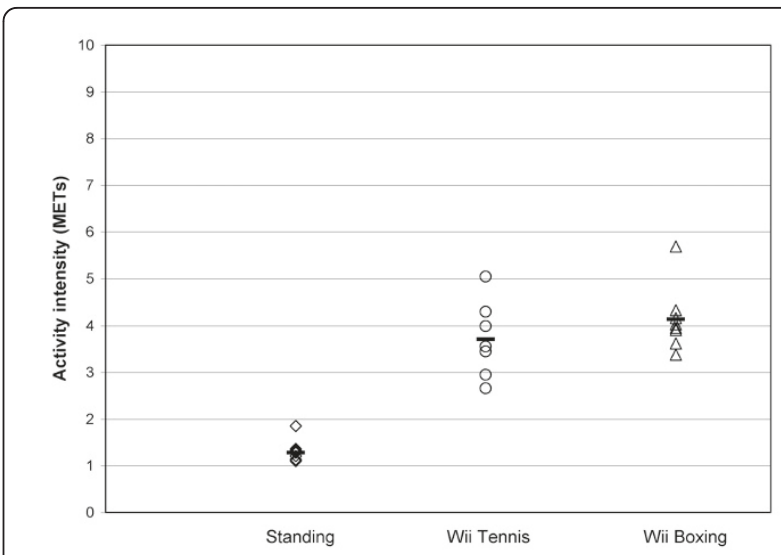

Figure 2 Participants' mean energy expenditure while standing and during Wii Sports tennis $(n=7)$ and boxing $(n=8)$ game play. Horizontal dashes indicate group mean energy expenditure. METs = metabolic equivalents.

\section{Discussion}

The aim of this study was to determine energy expenditure during Wii Sports tennis and boxing game play in chronic stroke patients. Our results show that the energy expenditure during Wii Sports boxing and tennis was $\geq 3$ METs for all except for one participant during tennis.

According to the ACSM/AHA guidelines for adults, the energy expenditure in these chronic stroke patients was sufficient to improve and maintain health [20]. Therefore, Wii Sports tennis and boxing may be useful to increase activity levels and to promote a healthy lifestyle in patients with stroke. The recommended activity

Table 3 Individual values for energy expenditure and rating of perceived exertion of the 15 minutes Wii game play

\begin{tabular}{ccccccc}
\hline Patient & Age & Gender & $\begin{array}{c}\text { Tennis } \\
\text { METs }\end{array}$ & $\begin{array}{c}\text { Tennis } \\
\text { RPE }\end{array}$ & $\begin{array}{c}\text { Boxing } \\
\text { METs }\end{array}$ & $\begin{array}{c}\text { Boxing } \\
\text { RPE }\end{array}$ \\
\hline 1 & 33 & $\mathrm{~m}$ & 2.7 & 3 & 4.3 & 4 \\
2 & 57 & $\mathrm{~V}$ & 4.3 & 3 & 3.4 & 4 \\
3 & 57 & $\mathrm{~m}$ & $\mathrm{na}$ & na & 4.2 & 8 \\
4 & 74 & $\mathrm{~m}$ & $\mathrm{na}$ & $\mathrm{na}$ & 4.0 & 0.5 \\
5 & 70 & $\mathrm{~m}$ & $\mathrm{na}$ & $\mathrm{na}$ & 5.7 & 3 \\
6 & 35 & $\mathrm{~V}$ & 3.4 & 5 & na & na \\
7 & 68 & $\mathrm{~V}$ & 3.6 & 4 & 3.9 & 9 \\
8 & 45 & $\mathrm{~m}$ & 3.0 & 5 & 4.0 & 6 \\
9 & 44 & $\mathrm{v}$ & 4.0 & 3 & 3.6 & 4 \\
10 & 52 & $\mathrm{~m}$ & 5.0 & 6 & na & na \\
\hline Mean & 53.6 & $\mathrm{na}$ & 3.7 & 4.1 & 4.1 & 4.8 \\
Median & 54.5 & $\mathrm{na}$ & 3.6 & 4.0 & 4.0 & 4.0 \\
Range & $33-74$ & $\mathrm{na}$ & $2.7-5.0$ & $3-6$ & $3.4-5.7$ & $0.5-9$ \\
\hline
\end{tabular}

METs = metabolic equivalents

$\mathrm{RPE}=$ rating of perceived exertion

na $=$ data are not available/applicable 
dose for healthy adults is moderate-intensity physical activity (3-6 METs) for a minimum of 30 minutes on five days each week or vigorous-intensity physical activity (> 6 METs) for a minimum of 20 minutes on three days each week [20]. Thirty minutes of moderate-intensity Wii activities could be attained by playing several 10-minute games of tennis or boxing. Alternatively, combinations of Wii Sports game play with other moderate-intensity activities (e.g., walking, dancing) could also be used to meet the ACSM/AHA target levels.

Defining aerobic intensity in absolute terms might not be appropriate for older adults and adults with chronic conditions, because they often have low fitness levels [4-6,41]. For older adults with low fitness levels, ACSM/AHA recommends the modified Borg scale to measure intensity of physical activity [41]. On this 10-point scale, a 5 to 6 is considered moderate-intensity activity and a 7 to 8 is considered vigorous-intensity physical activity. Six of our participants were 'older adults' (as defined by the ACSM/AHA guidelines; i.e. age $\geq 65$ years or age 50 to 64 years with clinically significant chronic conditions) of whom 3 scored $\geq 7$ on the modified Borg scale for boxing but had corresponding MET values $<6$. Because more intense activities are presumed to provide greater health benefits, these 3 participants might have greater health benefits than expected from their MET values [20]. Seven participants rated their perceived exertion $<5$ but had MET values $>3$, possibly as a result of the heterogeneity of fitness levels in our sample. Because of the possible differences in fitness levels and because the Borg scale is a subjective measure, we prefer to use the objective measured MET values.

Although expected, given the results from previous studies [42,43], the energy expenditure during Wii boxing was not significantly higher than during Wii tennis. Graves et al. [43] found higher energy costs in healthy persons during Wii boxing compared with Wii tennis. They suggested that this resulted from the nature of the boxing game encouraging the use of both arms, as nondominant limb activity was significantly greater than during tennis. Our participants were limited from using their affected arm during boxing, which might explain why differences in energy expenditure between boxing and tennis were not found.

Stroke survivors commonly have impaired balance while standing, which might induce relatively large energy costs during standing compared with sitting. The mean energy expenditure during standing (1.3 METs) was relatively low compared with energy expenditure during game play. Additionally, the MET intensities for standing in our sample were comparable with the MET intensities in able-bodied persons for standing quietly reported by Ainsworth et al. [8]. Therefore, the increased energy expenditure during Wii Sports resulted primarily from game play.
All participants were able to play Wii boxing without extensive instruction and training. Problems with timing of hitting the ball limited 3 participants from playing Wii tennis, most likely resulting from stroke-induced deficits in spatial and temporal coordination or reduced motor response from advanced age $[44,45]$. Holding the Wii remote and Nunchuk was not possible for one person because of severe spasticity in the fingers. This person could have played the games by simply fixating the Wii remote to the hand (e.g. using a latex band); however, additional assistance would be required to push the Wii remote buttons for starting and stopping the game. For safety reasons supervision is needed when a stroke patient with balance problems plays Wii games while standing. We found no adverse effects, (e.g. nausea or dizziness, repetition injuries, and epileptic seizure), which would limit the applicability of active video games as an exercise tool for stroke patients [21,46]. However, two patients felt temporarily very fatigued after boxing (perceived exertion of 8 and 9) and had mild soreness of the shoulder. Given current literature, repetition injuries seem to be the main concern when playing exergames [46-48]. Especially for stroke patients with musculoskeletal problems (e.g. muscle weakness and impaired joint stability), supervision is important to avoid exercise overdose.

This is a proof-of-principle study with a small convenience sample evaluating one 15-minute session of 2 Wii Sports games. The measurements were performed in a laboratory setting with two researchers observing the participant. However, we do not expect energy expenditure to differ substantially from home use because participants were instructed to play the games at their preferred intensity and manner, without encouragement by the researchers. Also, the participants wore a calorimeter face-mask, which differs from home use of the Wii; however, these caused no observable interference with game play. Nevertheless, we are aware that the participants were engaged in an experimental study; therefore, their behaviour will not necessarily be the same when playing Wii tennis and boxing at home. Larger prospective studies are needed to determine the effectiveness and potential side-effects of Wii game play for maintaining and improving health in chronic stroke patients. Also, future studies should focus on optimisation of exergames regarding hardware and software, so that a wide variety of stroke patients can enjoy and hopefully benefit from exergaming.

\section{Conclusions}

In general, Wii Sports tennis and boxing were performed by nearly all chronic stroke patients in this study at sufficient intensity to maintain and improve health. Further research is needed to determine the 
effectiveness of exergames in improving daily activity levels and cardiorespiratory fitness among stroke survivors. For this it is important to assess which stroke patient most likely will benefit from playing exergames.

\section{List of abbreviations}

none

\section{Acknowledgements and funding}

none

\section{Author details}

'Department of Rehabilitation Medicine and Physical Therapy, Erasmus MC University Medical Center, P.O. Box 2040, 3000 CA Rotterdam, The Netherlands. ${ }^{2}$ Rijndam Rehabilitation Centre, P.O. Box 2040, 3000 CA Rotterdam, the Netherlands.

\section{Authors' contributions}

HLH and RJBE contributed to the design and methodology of the study. MFSK and HLH contributed to the acquisition of the data. HLH, MFSK and RJBE analyzed the data, and HLH, GMR, HJS and RJBE interpreted the data. All authors read and approved the manuscript.

\section{Competing interests}

The authors declare that they have no competing interests.

Received: 23 November 2010 Accepted: 14 July 2011

Published: 14 July 2011

\section{References}

1. Donnan GA, Fisher M, Macleod M, Davis SM: Stroke. Lancet 2008, 371:1612-1623

2. Truelsen T, Piechowski-Jozwiak B, Bonita R, Mathers C, Bogousslavsky J, Boysen G: Stroke incidence and prevalence in Europe: a review of available data. Eur J Neurol 2006, 13:581-598.

3. Feigin $\mathrm{VL}$, Lawes $\mathrm{CM}$, Bennett DA, Anderson CS: Stroke epidemiology: a review of population-based studies of incidence, prevalence, and casefatality in the late 20th century. Lancet Neurol 2003, 2:43-53.

4. Gordon NF, Gulanick M, Costa F, Fletcher G, Franklin BA, Roth EJ, Shephard T, American Heart Association Council on Clinical Cardiology SoECR, Prevention the Council on Cardiovascular N, et al: Physical activity and exercise recommendations for stroke survivors: an American Heart Association scientific statement from the Council on Clinical Cardiology, Subcommittee on Exercise, Cardiac Rehabilitation, and Prevention; the Council on Cardiovascular Nursing; the Council on Nutrition, Physical Activity, and Metabolism; and the Stroke Council. Stroke 2004 35:1230-1240.

5. Ivey FM, Hafer-Macko CE, Macko RF: Exercise training for cardiometabolic adaptation after stroke. J Cardiopulm Rehabil Prev 2008, 28:2-11.

6. Pang MY, Eng JJ, Dawson AS, Gylfadottir S: The use of aerobic exercise training in improving aerobic capacity in individuals with stroke: a metaanalysis. Clin Rehabil 2006, 20:97-111.

7. Ivey FM, Hafer-Macko CE, Macko RF: Exercise rehabilitation after stroke. NeuroRx 2006, 3:439-450

8. Ainsworth BE, Haskell WL, Whitt MC, Irwin ML, Swartz AM, Strath SJ, O'Brien WL, Bassett DR Jr, Schmitz KH, Emplaincourt PO, et al: Compendium of physical activities: an update of activity codes and MET intensities. Med Sci Sports Exerc 2000, 32:S498-504.

9. Durstine $\mathrm{JL}$, Painter P, Franklin BA, Morgan D, Pitetti KH, Roberts SO: Physical activity for the chronically ill and disabled. Sports Med 2000, 30:207-219.

10. van de Port IG, Kwakkel G, van Wijk I, Lindeman E: Susceptibility to deterioration of mobility long-term after stroke: a prospective cohort study. Stroke 2006, 37:167-171.

11. Lee CD, Folsom AR, Blair SN: Physical activity and stroke risk: a metaanalysis. Stroke 2003, 34:2475-2481.

12. Liu M, Tsuji T, Hase K, Hara Y, Fujiwara T: Physical fitness in persons with hemiparetic stroke. Keio J Med 2003, 52:211-219.
13. Vermeer SE, Sandee W, Algra A, Koudstaal PJ, Kappelle L, Dippel DW Dutch TIATSG: Impaired glucose tolerance increases stroke risk in nondiabetic patients with transient ischemic attack or minor ischemic stroke. Stroke 2006, 37:1413-1417.

14. Sacco RL, Adams R, Albers G, Alberts MJ, Benavente O, Furie K Goldstein LB, Gorelick P, Halperin J, Harbaugh R, et al: Guidelines for prevention of stroke in patients with ischemic stroke or transient ischemic attack: a statement for healthcare professionals from the American Heart Association/American Stroke Association Council on Stroke: co-sponsored by the Council on Cardiovascular Radiology and Intervention: the American Academy of Neurology affirms the value of this guideline. Stroke 2006, 37:577-617.

15. Rimmer JH, Riley B, Wang E, Rauworth A, Jurkowski J: Physical activity participation among persons with disabilities: barriers and facilitators. Am J Prev Med 2004, 26:419-425.

16. Vissers $M$, van den Berg-Emons $R$, Sluis $T$, Bergen M, Stam H, Bussmann $H$ : Barriers to and facilitators of everyday physical activity in persons with a spinal cord injury after discharge from the rehabilitation centre. J Rehabil Med 2008, 40:461-467.

17. Morris $\mathrm{JH}$, Williams $\mathrm{B}$ : Optimising long-term participation in physical activities after stroke: exploring new ways of working for physiotherapists. Physiotherapy 2009, 95:228-234.

18. Miyachi M, Yamamoto K, Ohkawara K, Tanaka S: METs in adults while playing active video games: a metabolic chamber study. Med Sci Sports Exerc 2010, 42:1149-1153.

19. Lanningham-Foster L, Foster RC, McCrady SK, Jensen TB, Mitre N, Levine JA: Activity-promoting video games and increased energy expenditure. $J$ Pediatr 2009, 154:819-823.

20. Haskell WL, Lee IM, Pate RR, Powell KE, Blair SN, Franklin BA, Macera CA Heath GW, Thompson PD, Bauman A: Physical activity and public health: updated recommendation for adults from the American College of Sports Medicine and the American Heart Association. Med Sci Sports Exerc 2007, 39:1423-1434.

21. Rizzo A, Kim GJ: A SWOT analysis of the field of virtual reality rehabilitation and therapy. Presence: Teleoper Virtual Environ 2005 14:119-146.

22. Betker AL, Desai A, Nett C, Kapadia N, Szturm T: Game-based exercises for dynamic short-sitting balance rehabilitation of people with chronic spinal cord and traumatic brain injuries. PhysTher 2007, 87:1389-1398.

23. Saposnik G, Teasell R, Mamdani M, Hall J, Mcllroy W, Cheung D, Thorpe KE, Cohen LG, Bayley M, Stroke Outcome Research Canada Working G: Effectiveness of virtual reality using Wii gaming technology in stroke rehabilitation: a pilot randomized clinical trial and proof of principle. Stroke 2010, 41:1477-1484.

24. Holden MK, Gill KM, Magliozzi MR, Nathan J, Piehl-Baker L: Clinical gait assessment in the neurologically impaired. Reliability and meaningfulness. Phys Ther 1984, 64:35-40.

25. Bamford J, Sandercock P, Dennis M, Burn J, Warlow C: Classification and natural history of clinically identifiable subtypes of cerebral infarction. Lancet 1991, 337:1521-1526.

26. Gregson JM, Leathley MJ, Moore AP, Smith TL, Sharma AK, Watkins CL: Reliability of measurements of muscle tone and muscle power in stroke patients. Age Ageing 2000, 29:223-228

27. Gregson JM, Leathley M, Moore AP, Sharma AK, Smith TL, Watkins CL: Reliability of the Tone Assessment Scale and the modified Ashworth scale as clinical tools for assessing poststroke spasticity. Arch Phys Med Rehabil 1999, 80:1013-1016.

28. Blum L, Korner-Bitensky N: Usefulness of the Berg Balance Scale in stroke rehabilitation: a systematic review. Phys Ther 2008, 88:559-566.

29. van Swieten JC, Koudstaal PJ, Visser MC, Schouten HJ, van Gijn J: Interobserver agreement for the assessment of handicap in stroke patients. Stroke 1988, 19:604-607.

30. Wii. [http://en.wikipedia.org/wiki/Wii].

31. Wii remote. [http://en.wikipedia.org/wiki/Wii_Remote].

32. Durnin JV, Womersley J: Body fat assessed from total body density and its estimation from skinfold thickness: measurements on 481 men and women aged from 16 to 72 years. Br J Nutr 1974, 32:77-97.

33. Duffield $R$, Dawson $B$, Pinnington HC, Wong P: Accuracy and reliability of a Cosmed K4b2 portable gas analysis system. J Sci Med Sport 2004, 7:11-22 
34. Maiolo C, Melchiorri G, lacopino L, Masala S, De Lorenzo A: Physical activity energy expenditure measured using a portable telemetric device in comparison with a mass spectrometer. Br J Sports Med 2003, 37:445-447.

35. Littlewood RA, White MS, Bell KL, Davies PS, Cleghorn GJ, Grote R: Comparison of the Cosmed K4 b(2) and the Deltatrac II metabolic cart in measuring resting energy expenditure in adults. Clin Nutr 2002, 21:491-497.

36. McLaughlin JE, King GA, Howley ET, Bassett DR Jr, Ainsworth BE: Validation of the COSMED K4 b2 portable metabolic system. Int J Sports Med 2001, 22:280-284.

37. Pinnington $\mathrm{HC}$, Wong $\mathrm{P}$, Tay J, Green $\mathrm{D}$, Dawson B: The level of accuracy and agreement in measures of FEO2, FECO2 and VE between the Cosmed K4b2 portable, respiratory gas analysis system and a metabolic cart. J Sci Med Sport 2001, 4:324-335.

38. Hausswirth C, Bigard AX, Le Chevalier JM: The Cosmed K4 telemetry system as an accurate device for oxygen uptake measurements during exercise. Int J Sports Med 1997, 18:449-453.

39. Wilson RC, Jones PW: A comparison of the visual analogue scale and modified Borg scale for the measurement of dyspnoea during exercise. Clin Sci (Lond) 1989, 76:277-282.

40. Borg GA: Psychophysical bases of perceived exertion. Med Sci Sports Exerc 1982, 14:377-381.

41. Nelson ME, Rejeski WJ, Blair SN, Duncan PW, Judge JO, King AC, Macera CA, Castaneda-Sceppa C: Physical activity and public health in older adults: recommendation from the American College of Sports Medicine and the American Heart Association. Med Sci Sports Exerc 2007, 39:1435-1445.

42. Graves L, Stratton G, Ridgers ND, Cable NT: Comparison of energy expenditure in adolescents when playing new generation and sedentary computer games: cross sectional study. BMJ 2007, 335:1282-1284.

43. Graves LE, Ridgers ND, Stratton G: The contribution of upper limb and total body movement to adolescents' energy expenditure whilst playing Nintendo Wii. EurJ ApplPhysiol 2008.

44. Fang Y, Yue GH, Hrovat K, Sahgal V, Daly JJ: Abnormal cognitive planning and movement smoothness control for a complex shoulder/elbow motor task in stroke survivors. J Neurol Sci 2007, 256:21-29.

45. Seidler RD, Bernard JA, Burutolu TB, Fling BW, Gordon MT, Gwin JT, Kwak Y, Lipps DB: Motor control and aging: links to age-related brain structural, functional, and biochemical effects. Neurosci Biobehav Rev 2010, 34:721-733.

46. Crosbie JH, Lennon S, Basford JR, McDonough SM: Virtual reality in stroke rehabilitation: still more virtual than real. Disabil Rehabil 2007, 29:1139-1146, discussion 1147-1152.

47. Bonis J: Acute Wiiitis. NEnglJ Med 2007, 356:2431-2432.

48. Cowley AD, Minnaar G: New generation computer games: Watch out for Wii shoulder. BMJ 2008, 336:110.

doi:10.1186/1743-0003-8-38

Cite this article as: Hurkmans et al:: Energy expenditure in chronic stroke patients playing Wii Sports: a pilot study. Journal of NeuroEngineering and Rehabilitation 2011 8:38.

\section{Submit your next manuscript to BioMed Central and take full advantage of:}

- Convenient online submission

- Thorough peer review

- No space constraints or color figure charges

- Immediate publication on acceptance

- Inclusion in PubMed, CAS, Scopus and Google Scholar

- Research which is freely available for redistribution

Submit your manuscript at www.biomedcentral.com/submit
Biomed Central 